\section{EL SUR, ESPACIO DEL RECUERDO, EN LA OBRA DE \\ CONCHA LAGOS}

SOUTH, SPACE OF THE MEMORIES, IN THE WORK OF CONCHA LAGOS

Mª Jesús Soler Arteaga

Universidad de Sevilla

Resumen:

Abstract:

El tratamiento del espacio y del tiempo son Space and time are essential in literature, vitales en la literatura, independientemente independently of the literary gender, and the del género literario, la amplia producción de wide production of Concha Lagos gives signs Concha Lagos es testigo de ello, sobre todo of it, above all on her reflections on the South en sus reflexiones sobre el sur. El objetivo de The aim of this study is to analyse the role of este estudio es analizar el papel del espacio the space in the collection of poems of Conch en el poemario de Concha Lagos recogido en Lagos collected by Emilio Miró in 1976 and its Cor Emilio Miro en importance in the texts.

1976y su importancia a lo largo de los textos.

Palabras claves:

Concha Lagos, poema, tiempo, espacio.

KEY WORD:

Cincha Lagos, poem, time, space.
El tratamiento del espacio y sus funciones enla literatura han sido objeto denumerosos y esclarecedores estudios, en los que se ha puesto de manifiesto el importante papel que juega no sólo como marco, sino también como organizador y estructurante textual. Estos aspectos han sido ampliamente abordados desde la fenomenología poética, desde la narratología; y actualmente en la formulación de la teoría del emplazamiento. Estas son las consideraciones que tomaremos como punto de partida en nuestro análisis de la presencia del Sur en la obra de la autora andaluza Cocha Lagos.

La actividad de la Asociación Andaluza de Semiótica a lo largo de estos años ha propiciado la publicación de muchos trabajos en los que ha sido constante la reflexión sobre el sur, especialmente sobre Andalucía, en tanto que es territorio del sur, y la construcción de la realidad y la identidad andaluza. En este sentido es muy significativa la aportación de Juan Antonio Bermúdez recogida en las actas del VI Simposio, en la que hacía un profundo análisis del Sur como espacio mítico, considerándolo como un territorio de límites imprecisos, que no se definen exclusivamente con un criterio geográfico, sino en una relación de oposición con el norte:

Frente al Norte provisional y distante, siempre incógnito y ajeno, extraño, el Sur queda ligado a lo terrenal y, por extensión a lo firme, al origen, al pasado; se constituye así como un punto de partida menor, peor, inferior, en la progresión mediante la vida; pero esto mismo lo hace perdurar como referencia, como el estimonio constante de una perdida. (Bermúdez, 2000:108)

El espacio, como afirma Gilbert Durand, es un forma "a priori" de la imaginación en la que las categorías de la fantástica se integran "dándole sus dimensiones afectivas: elevación y dicotomía trascendente, inversión y profundidad íntima y, por último, poder infinito de repetición." Por tanto estas dimensiones que configuran el espacio afectan a los puntos cardinales, a los que también se refiere Durand citando las divisiones geográficas y fantásticas de otros autores, que como la de Soustelle son aplicables a otros espacios puesto que "muestra en primer lugar que el espacio fantástico se divide en dos grandes terrenos antagónicos: el este, oriente de la luz renaciente y victoriosa, opuesto al Oeste, país del misterio, del declive. A su vez estos terrenos están reduplicados por el Norte, país del frío, de la guerra, de la muerte, y por el país tropical, 'país de las espinas'"' (Durand, 1982: 394).

De lo dicho hasta el momento podemos desprender que así como se establece esta relación de oposición entre norte y sur otorgándose a cada territorio unas características y cualidades específicas, contrarias entre ambos; el pensamiento humano a través de distintas formas, y concretamente de la literatura, que es el ámbito que nos ocupa, se ha encargado de perpetuar esta división esquemática, a menudo incorporando nuevos rasgos distintivos a uno $\mathrm{u}$ otro. Muy lejos de la imagen arquetípica que nos ofrecen 
Durand o Bermúdez del sur con respecto siempre a su contrario, se situa la visión que del sur codificaron los viajeros románticos y cuya vigencia ha perdurado.

Los autores románticos europeos no sólo volvieron sus ojos hacia la tradición literaria española de la que tomaron algunos temas 'el hombre natural' o 'el orientalismo', como señala Guillermo Díaz-Plaja en su Introducción al estudio del romanticismo español, sino que incluyeron a España en sus recorridos como un destino rebosante de exotismo en el que los atributos del sur, el país tropical, y del este, el oriente, se mezclaban. Emilio Temprano advierte en su libro España. La selva de los tópicos, que la imagen que nos ofrecen estos viajeros es una imagen completamente desenfocada puesto que para ellos "España era solamente Andalucía" y ésta era Andalucía para ellos: La Andalucía que nos describen estos viajeros, por lo demás no era demasiado real, sino efectista y abigarrada con mucho pintoresquismo y 'coleur locale' donde no podían faltar los bandoleros de patilla ancha y trabuco, los gitanazos y gitanazas de mirada retadora, danzas orientales y turbantes moriscos, decadencia y fanatismo, cante jondo, atraso, toreros sangrientos con pasiones de fuego, mujeres ardorosas con la peineta clavada en el moño y el puñal en la liga, contrabandistas...(Temprano, 1988: 41)

En contraposición con esta imagen repleta de tipos folclóricos estereotipados que pueblan la literatura de la época está la que presentan los poetas andaluces, que poco o nada tiene que ver con la anterior, y será la que más nos interese puesto que al referirnos a una poeta cordobesa trataremos de establecer su vinculación a esta segunda visión. La idea del sur puede ser tan varia como autores tengamos en cuenta, pero es difícil no advertir el tono nostálgico y melancólico que tienen en común Antonio Machado, Luis Cernuda, etc, frente a la exaltación de la belleza y el colorido en la poesía de otros como Federico García Lorca.

Fernando Ortiz en las palabras liminares que acompañan a una selección en la que reúne algunos de sus ensayos acerca de poetas andaluces, presta especial atención a la huella que el destierro ha dejado en ellos desde el romanticismo hasta nuestros días, ya sea a causa del exilio, o de la emigración por circunstancias propias; al mismo tiempo incide en la ambigua relación establecida entre estos autores y su tierra, que propicia la evocación de esta tierra que nunca les perteneció y que resulta 'irreal y fantasmagórica'; y afirma que no "es casual que el poeta entone su canto con voz elegiaca -en la que con frecuencia late el mismo hondo lamento resignado de los cantes del pueblo- o bien prefiera negar la realidad por medio de fantasías compensatorias, creando mundos edénicos e irreales" (Ortiz, 1995: 20), apoyando esta hipótesis en un origen común "la realidad insatisfactoria de Andalucía".

Este es el caso de Concha Lagos, seudónimo con el que es conocida en los ambientes literarios Concepción Gutiérrez Torrero, nacida en Córdoba en 1913 y perteneciente a la Real Academia de Córdoba. Su infancia y juventud transcurrieron en Andalucía, sin embargo la mayor parte de su vida transcurrió en Madrid y este alejamiento de su tierra deja una profunda huella tanto en su vida personal como en su obra literaria, a la que haremos una breve referencia.

Sin duda al examinar la producción de Concha Lagos destaca su extensión y su reconocida calidad en todos los géneros. Su obra en prosa comprende los siguientes títulos: El pantano (1954), Al sur del recuerdo (1955), La hija de Jairo (1963) y La vida y otros sueños (1969). En sus narraciones las referencias a su tierra son una constante, en ellas el paisaje perdido y añorado del sur se recupera y se reescribe. También realizó algunas tentativas en el género dramático, prueba de ello son las dos obras de teatro que publicó: Después del mediodía y Ha llegado una carta.

Su labor literaria no se ciñe exclusivamente a la publicación de sus libros, durante años colaboró intensamente con publicaciones españolas e hispanoamericanas. Desde los años cincuenta participó con Rafael Millán en la revista Ágora, cuadernos de poesía y posteriormente en la continuación de esta, Cuadernos de Ágora. Ambos títulos y la colección del mismo nombre, fueron parte del mismo proyecto que pretendía dar difusión a poetas españoles e hispanoamericanos. Colaboró en homenajes y números especiales de muchas revistas con poemas, prosas, y artículos, entre estas publicaciones destacaremos: Poesía española; Grimpola, pliego de poesía publicado a partir de 1957 por el Aula de Cultura de la Escuela Nacional de Artes Gráficas, caracterizado por la presencia de voces femeninas; la revista Cantalapiedra, publicada en Santander por Aurelio G. Cantalapietra; El Cobaya, editada en Ávila por el grupo "El Cobaya"; en Rocamador, de Palencia; en el Pliego Crítico anexo a la revista Archivum de la Universidad de Oviedo, dirigido por E. Alarcos y J. M. Martínez Cachero; y en Hontanar, dirigida por José M.a Osuna y patrocinada por el Ayuntamiento de Cazalla.

Pero en lo que más sobresale el quehacer literario de Concha Lagos es en el género lírico, por la expresividad de su estilo y por la ternura con la que afronta las temáticas del amor, la soledad, la tierra, la frustración, el tiempo, la condición de mujer como una imposibilidad ${ }^{1}$, y también la fe (en muchos poemas la autora se dirige a Dios haciendo de sus versos una oración). Aunque las décadas de los cincuenta y los sesenta serán las más significativas en su trayectoria, su obra poética la forman una veintena de libros publicados entre 1954 y 1980: Balcón (1954), Los obstáculos (1955), El corazón cansado (1957), La soledad de siempre (1958), Arroyo claro (1958), Agua de Dios (1958), Luna de enero (1960), Campo abierto (1960), Tema fundamental (1961), Golpeando el silencio

1 Poemas como el contenido en Los obstáculos (1955) "Miradme bien...": ... Yo quisiera fundirme en el río de la vida / y arqueando los brazos crear puentes, / unir orillas; / sentir vuestras pisadas en desfile compacto. / No sonriáis: ya sé que soy mujer. O el contenido en El corazón cansado (1957) "Elegía a las manos": Tal vez por ser mujer se me vuelan las manos /en busca de algo frágil y pequeño /Para poderlo alzar hasta el regazo. / ...a veces, nuestras manos, por el aire, / van recortando barcos de papel / para el pasaje de los desalientos. ¡Cómo duelen las manos en la espera! / Las manos no descansan, / ahondan agujeros en el sueño, / siempre buscando amor, cosas perdidas... 
(1961), Canciones desde la barca (1962), Para empezar (1963), Los anales (1966), Diario de un hombre (1970), El cerco (1971), La aventura (1973), Fragmentos en espiral desde el pozo (1974), Antología (1976), Gótico florido (del que se avanzaban algunos poemas en Antología) y Por las ramas (1980) con la que consiguió el Premio Ámbito Literario.

En nuestro análisis nos centraremos únicamente en su producción poética y concretamente en la recogida en la antología preparada por Emilio Miró en 1976, en la que ofrece un amplio recorrido por la obra de C. Lagos desde su primer libro Balcón, hasta Gótico Florido. Ya desde el principio señalábamos que el espacio puede cumplir una función de marco, pero también es frecuente que actúe como estructurante y que sea indisoluble de aquello que se cuenta; esto es lo que sucede a lo largo del poemario en el que la presencia del sur es incuestionable aunque en algunos libros como Arroyo claro o Canciones desde la barca, es aún más patente.

De Arroyo claro son dos fragmentos que nos darán una clave importante para apreciar qué es el sur para C. Lagos y cuál ese sur concreto que se encuentra en la esencia de muchos poemas; ambos fragmentos pertenecen a dos poemas que E. Miro (1976: 20) no antóloga pero que cita en la introducción de su edición como dos ejemplos en los que se pueden observar el sueño, el recuerdo y el amor como temas constantes y fundamentales en su obra:

$$
\begin{aligned}
& \text {...aunque diga ya que siempre } \\
& \text { sur o norte me da igual } \\
& \text { golpeando está el recuerdo } \\
& \text { como lluvia en el cristal. } \\
& \text { Cruzados nuestros caminos } \\
& \text { Como barcos en el mar. } \\
& \text { Tú rumbo siempre a tu norte, } \\
& \text { yo, hacia mi sur a soñar. }
\end{aligned}
$$

En ambos fragmentos se plantea la disyuntiva norte - sur, para decantarse en los dos casos por el sur, ésta es la única opción válida pues aunque para el yo protagonista sea indiferente una u otra el recuerdo le insta a dar una respuesta en el primero, y en el segundo el sur es su destino pues sólo allí tiene cabida el sueño. El recuerdo y el sueño son los motores fundamentales de su creación pues como dice E. Miró "memoria y sueño llenan la vida, colman el vacío y levantan e iluminan la palabra poética".

La palabra recuerdo va siempre unida al paisaje y nos remite al pasado; otro ejemplo de este uso constante podemos encontrarlo en un fragmento de otro poema de Arroyo Claro: ..."Por este paisaje un día...", / me gritaban los recuerdos. /Yo haciendo por olvidar, / ellos siempre removiendo... (p. 69). Esta relación necesaria que se establece entre el espacio y el tiempo puede explicarse perfectamente con la noción de cronotopo aportada por M. Bajtin: En el cronotopo artístico tiene lugar la unión de los elementos espaciales y temporales en un todo inteligible y concreto:
El tiempo se condensa aquí, se comprime, se convierte en visible desde el punto de vista artístico; y el espacio, a su vez, se intensifica, penetra en el movimiento del tiempo, del argumento, de la historia. Los elementos de tiempo se revelan en el espacio, y el espacio es entendido y medido a través del tiempo. La intersección

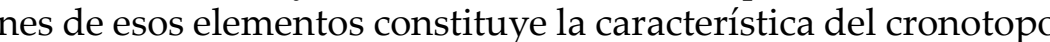
artístico. (Bajtin, 1989: 237-238).

Sabemos que el espacio y el paisaje al que se refiere C. Lagos es al del sur, pero debemos concretar más a qué lugares precisos, y a la vez a qué tiempo; el tiempo lo hemos situado en el pasado, por tanto las referencias al espacio nos remiten a aquellos lugares de Andalucía que la autora conoció y a los que sólo puede volver a través de la memoria. En esta idea de la indisolubilidad espacio temporal y en la certeza de que el ser humano pertenece a unas determinadas coordenadas espacio-temporales se sustenta la Teoría del emplazamiento que arroja luz a este punto en el que nos encontramos: Pero esa estructura de emplazamiento no se limita a ubicarnos externamente; no es algo accidental sino, precisamente, el marco, el horizonte, el escenario desde el que se dibuja lo esencial, pero ya hecho nuestro, formando parte de nosotros. Estar emplazado es, pues, también sentirse instados a dar una respuesta, un testimonio, en un determinado lugar y tiempo. (Vázquez Medel, 2000: 124)

El yo lírico protagonista de estos poemas vuelve a su casa, al huerto o al jardín que tal vez tuvo la casa de Concha Lagos en Córdoba, al Valle del Guadalquivir, a los paisajes que le eran familiares, en los que transcurrieron su infancia y su juventud verdadera para transformase en materia poética; en un lugar que el lector no sabe si existió pero que asimila tan fácilmente a su propio recuerdo que le resulta verosímil; aunque no sea andaluz, porque sí fue niño. A este respecto son significativas las palabras de Mircea Eliade cuando se refiere a la concepción arcaica de la beatitud y la perfección de los orígenes que sólo el psicoanálisis ha calificado como primordial y paradisíaco, esto podemos constatarlo en el siguiente fragmento del poema "Penúltima elegía" (1976: 293-294) perteneciente al libro El cerco:

...Mi infancia fue un prodigio de luces y horizontes.

Por eso, cuando el tiempo me trajo pena y llanto,

volvía la mirada

regresaba a mi mundo

bendiciendo la tierra de los pasos primeros.

En ella frutos, soles, aromas y jla casa!

La casa con sus ojos para la ruta de los vuelos.

De ventanas afuera siempre un coro de cantos.

Puerta adentro, ¡Dios mío!, nanas y arrullos

mezclados a lo cotidiano[...]

...La mano extiendo y testifico

y juro que existió

fue el mejor paraíso aquí en la tierra. 
De este fragmento destacaremos dos aspectos que son los que vamos a desarrollar a continuación: en primer lugar la referencia explícita a la infancia, y en segundo la oposición dentro - fuera, empleada por Bachelard, y sustentada en dos elementos espaciales la casa y el paisaje. Con respecto a la infancia insistiremos en la contraposición que realiza entre los años infantiles calificados como prodigiosos y paradisíacos, y los años que vendrían después tan poco gratos que los menciona brevemente y vuelve a la edad dorada de la infancia.

La propia autora había utilizado como introducción en uno de sus libros una cita de Rilke que dice así: "Un poeta es su infancia"; y son numerosos los poemas en los que la autora cordobesa vuelve a su niñez, para construir con retazos de ésta poemas con una fuerte carga descriptiva y sentimental ejemplos de esto son: "Elegía a una clase"2, perteneciente al libro Golpeando el silencio, en el que incluso podemos observar ciertos ecos machadianos; o los del poemario Para empezar "Elegía en tres tiempos", "En busca de la niñez" y "Elegía a una calle"(1976:184) en este último el tono nostálgico se va transformando desde la visión de la calle que guardaba en la memoria a la que tiene en ese momento y el recuerdo se vuelve doloroso porque ni siquiera la memoria puede abolir el tiempo: La niebla me la puso tan distante / que hasta llegó a cansarme la memoria, / y era la misma calle con su fuente.[...] / ... Me duele la memoria esta mañana / como duele mirar fotografías / cuando los rostros se nos vuelven tiempo / tiempo de piedra por el largo olvido. / Aunque es la misma calle con su fuente, / Con vida renovada y nueva, / lápida con fechas se me ha vuelto.

El otro aspecto que podemos analizar a partir del poema "Penúltima elegía" es la oposición dentro - fuera; en este caso ambos elementos se complementan y realizan la misma función poner en contacto al yo lírico con sus sentimientos. El espacio interior está representado por la casa protagonista de otros poemas, especialmente con aquellos elementos que marcan la frontera entre el interior y el exterior: el jardín, la huerta, y por supuesto ventanas y balcones desde los que la protagonista se contempla a si misma; G. Bachelard se interroga sobre el mayor beneficio que proporciona la casa, su respuesta es que la casa alberga el ensueño y protege al soñador permitiéndole soñar en paz, y añade acerca del ensueño que a este pertenecen los valores que marcan al hombre en su profundidad y que tiene el privilegio de la autovaloración. El espacio exterior representado por la ciudad, el río, los caminos, etc., símbolos que nos remiten igualmente a la intimidad; Bachelard analizó también espacios simbólicos surgidos de la contemplación de la inmensidad para concluir que: “...descubrimos aquí que la inmensidad del aspecto íntimo, es una intensidad, una intensidad del ser; la intensidad

2 Clase de las pequeñas con ventana al jardín / con muros de naranjos y murmullo de alberca, / con cielos para el vuelo por la ruta del sol / como la golondrina, o tal vez la cigarra / que también se sacude afanes de no importa. / Que si cuatro más cuatro, que si cinco más cinco... que se desarrolla en una vasta perspectiva de inmensidad íntima."(Bachelard, 1994: 231).

Sin embargo, pese al gran número de poemas repletos de imágenes con una fuerte carga afectiva, que forman este grupo; hay otro grupo de poemas que tanto por las imágenes y el lenguaje como por la estructura métrica que presentan, nos remiten a un tipo de poesía popular, colorista y llena de tópicos referidos siempre al paisaje. Así encontramos poemas dedicados a Córdoba, a Ronda, a Almería, en los que la poesía popular se mezcla con los versos de Machado o Lorca:

Por el llano y por la sierra

Alto viento se levanta,

Viento que a Córdoba lleva

-Que nadie diga que el aire

pasó por ella sin verla.-

..."Córdoba callada y sola"

dijo una voz verdadera.

Voz que sabe de silencios

en aire azul se nos queda

(Canciones desde la barca, 1976: 172)

También es frecuente la aparición del Guadalquivir tanto como elemento espacial como protagonista, que recupera su nombre, aunque el lector intuye que ese río símbolo del paso del tiempo que aparece en multitud de ocasiones tiene un referente real, por ejemplo en el poema "Elegía en tres tiempos": Estoy en nuestro puente. / Sigue el agua / su tiempo y su costumbre río abajo /... estamos en ayer mirando el río, / preguntando el porqué de la alta noche /... Es difícil no pensar en esa imagen emblemática de Córdoba y del puente de San Rafael, al que también Lorca había dedicado el poema titulado "San Rafael". Aunque quizás la referencia más significativa se encuentre en "E retardado" perteneciente al libro El cerco en el que el yo poético en un tono confesional dialoga con el río al que llama "mi Guadalquivir señero".

En cuanto a las referencias humanas son escasas pero exceptuando el tú amoroso al que alude en muchos poemas o el diálogo con algunos poetas, la autora evita la alusión a personajes arquetípicos, que mencionábamos al principio, y apenas hay una referencia al campesino, al cantaor ${ }^{3}$, a las niñas y en una sola ocasión a los andaluces: Que lo digan, que lo digan / desde ventanas y torres; / que lo canten en la rueda / niñas de canela y bronce. / Los andaluces, Dios mío, /¿por qué caminos? ¿Por dónde? (1976: 164). En estos versos de Canciones desde la barca se hace patente la angustia por el destino incierto de los andaluces que se marchaban, hay que tener en cuenta que el libro se publicó en 1962 y en esos años se produjo una fuerte emigración.

Para concluir diremos que en la obra de C. Lagos se unen las dos tendencias que F. Ortiz señalaba en los poetas andaluces; probablemente porque el sur de esta autora es

3 Para el que cantando llora / y le cuenta a la guitarra / la pena de cada hora... ( de Canciones desde la barca, 1976: 165. 
un emplazamiento de la memoria que existió en un momento y se recrea y actualiza al escribir. La escritura se convierte no sólo en un testimonio nostálgico y personal, sino también un testimonio de amor hacia su tierra en el que tiene cabida algunos lugares comunes, toda la belleza y también la realidad social.

\section{REFERENCIAS BIBLIOGRÁFICAS}

Bachelard, G., La poética del espacio, México, Fondo de Cultura Económica, 1994

Bermúdez Bermúdez, J. A., "El sur como espacio mítico” en Vázquez Medel, M. A. y Acosta, Á. (eds.) La semiótica actual. Aportaciones del VI Simposio Internacional de la Asociación Andaluza de Semiótica, Sevilla, Alfar, 2001.

Batjín, M., Teoría y estética de la novela, Madrid, Taurus, 1989.

Díaz Plaja, G., Introducción al estudio del romanticismo español, Madrid, Espasa-Calpe S.A. Colección Austral, 1980.

Durand, G., Las estructuras antropológicas de lo imaginario, Madrid, Taurus, 1982.

Lagos, C., Antología: (1954-1976), Barcelona, Plaza \& Janés, 1976.

Eliade, M., Mito y realidad, Barcelona. Labor, 1994.

Ortiz, F., La estirpe de Bécquer, Sevilla, Biblioteca de Cultura Andaluza, 1995.

Rubio, F., Las revistas poéticas españolas (1939-1975), Madrid, Turner, 1976.

Temprano, E., La selva de los tópicos, Madrid, Mondadori, 1988.

Vázquez Medel, M. Á., "Del escenario espacial al emplazamiento", en Sphera publica. Revista de Ciencias Sociales y de la Comunicación, Número 0 (2000) Murcia.

VVAA, Enciclopedia de Andalucía, Edit. Anel. Tomo V, 1979. 